\title{
ARTERIOSCLEROSIS AND THE PROMISE OF GPIIB/IIIA INHIBITORS IN STROKE
}

\author{
GUSTAVO SAPOSNIK*, LOUIS R CAPLAN**
}

\begin{abstract}
Ischemic mechanisms in patients with brain and heart attacks have been studied for more than 150 years. Antiplatelets agents did show benefit in secondary prevention. Aspirin is the most common antiaggregant in clinical use today. However, the benefit produced by the "best" antiplatelet regimen in stroke prevention is lower than $40 \%$. The adherence of circulating platelets to the subendothelium is mediated by glycoprotein (GP) residing on the cell's surface. GPIIb/IIIa is the most important platelet membrane receptor that mediates the process of platelet aggregation, and thrombus formation. Thus, new drugs that block the GPIIb/IIIa receptor have recently emerged. Clinical trials using these agents have shown effectiveness in acute coronary syndromes. However, the absence of studies in cerebrovascular disease and the potential hemorrhagic complications questioned their use in stroke prevention. We review the clinical trials using the new GPIIb/IIIa agents in myocardial ischemia, and consider the potential implications for cerebrovascular disease.
\end{abstract}

KEY WORDS: glycoprotein IIb/IIIa inhibitors, stroke, atherogenesis

\section{Arteriosclerosis y nuevas perspectivas de los inhibidores del receptor GPIIb/IIIa en stroke}

RESUMEN - Los mecanismos de isquemia en infarto de miocardio y enfermedad cerebrovascular (ECV) han sido estudiados por mas de 150 años. Drogas antiplaquetarias mostraron un beneficio en la prevención secundaria. La aspirina es el mas común de los antiagregantes usados en la practica clínica. No obstante, el beneficio producido, aun con el "mejor" tratamiento antiagregante, en la prevención de ECV es inferior al 40\%. La adhesión plaquetaria es un proceso mediado por glicoproteinas (GP) de la membrana celular. GPIIb/IIIa es un receptor de membrana plaquetaria que interviene en el proceso de agregación plaquetaria y formación del trombo. Estudios clínicos con nuevos agentes que bloquean a este receptor mostraron ser efectivos en los síndromes coronarios agudos. No obstante, la falta de estudios en ECV y las potenciales complicaciones hemorrágicas, limitan su uso en la prevención de stroke. Revisamos los mecanismos de trombogenésis y los estudios clínicos con los nuevos agentes GPIIb/ IIIa, considerando sus implicancias en ECV.

PALABRAS-CLAVE: inhibidores receptor GPIIb/IIIa, enfermedad cerebrovascular, arteriosclerosis

The pathophysiological mechanisms of ischemia in coronary and cerebrovascular disease are similar. This mechanism implicate a primary reduction of blood flow in both syndromes.

The vulnerability of atheromatous plaques depends on the size and consistency of the core, and the thickness of the fibrous cap (sclerotic component). The thinnest the fibrous cap, the highest the risk of rupture (unstable plaque). The disruption or erosion of an unstable plaque has been documented in postmortem coronary arteries. However, cerebral and coronary vessels have significant anatomic, histologic, and clinical profile differences affecting their clinical correlations.

*M.D., Department of Neurology, Ramos Mejia Hospital, Buenos Aires University, Argentina; **M.D., Department of Neurology, Stroke Unit, Deaconess Medical Center, Harvard Medical School, Boston (330 Brookline Ave. Beth Israel Boston, MA 02215. USA).

Dr. Gustavo Saposnik - Charcas 44314 “10” - Buenos Aires (1425) - Argentina. Fax 54114803 8674. E-mail: gsaposnik@yahoo.com 
Antiaggregant treatment has demonstrated benefit to prevent also heart and brain attack, but with different success rates: 50-60\% risk reduction at 2 years for myocardial infarction (MI) ${ }^{1}$, and $25 \%$ for stroke ${ }^{2}$.

We herein review briefly the mechanisms of plaque disruption and then we will analyse recent trials using glycoprotein (GP) - GPIIb/IIIa - inhibitors focus on the potential implications in cerebrovascular disease.

\section{Arterial occlusion: background and evidence}

Ischemic mechanisms have been studied for more than 150 years. In 1847, Virchow ${ }^{3}$ analyzed 76 autopsies, and found blood clots in $24 \%$ of the veins of the extremities. He then performed experiments showing that foreign bodies placed in the veins of animals moved toward the heart and were found in the lungs. He also found clots obstructing brain, renal, splenic, and limb arteries in patients with valve disease and left atrial thrombi. He was the first who recognized arterial obstruction in situ (thrombosis) and at a distance (embolism).

Foix, Hilleman and Ley $^{4}$ studied the vascular pathology in arteries supplying brain infarcts. Among 56 cases, they found total occlusion in $21 \%$, partial occlusion in $25 \%$, and patent in the remaining $54 \%$ of the arteries that supplied the infarct. Despite their confusion about the lack of obstruction in these arteries, they hypothesized several mechanisms: embolic, low flow, vasoconstriction or that the arterial occlusion could be followed by brain softening and would have developed later.

The correlation between ischemic mechanisms and the related clinical syndromes developed in the mid $20^{\text {th }}$ century with Miller Fisher's paper on carotid artery occlusion in $1951^{5}$, suggesting that intra-arterial embolism was a very important stroke mechanism. However, there are not much more data on the intrinsic vessel mechanism for stroke.

In 1986, Miller Fisher and Ojemann ${ }^{6}$ studied more than 1000 carotid segments. Most patients with severe stenosis had mural thrombi or platelet-aggregates within arterial ulcerations, irregularities and crevices. In addition, the analysis of 60 carotid plaques removed using microscopic sections in the NASCET-ACAS Plaque Project ${ }^{7}$ revealed fissure-ulceration in $83 \%$, hemorrhage in $57 \%$, and thrombus in $30 \%$ of the plaques. There was no association in the frequency of hemorrhage between those patients with or without aspirin (ASA) usage. The authors concluded that intra-plaque hemorrhage is associated with increasing stenosis.

One year later, Ogata et $\mathrm{al} .{ }^{8}$ based on autopsy analysis, concluded that plaque rupture or intraplaque hemorrhage is not an essential condition for cerebral thrombosis, and non-occlusive mural thrombosis can occur even in the absence of plaque disruption.

However, there is not general agreement among authors about what is the underlying cause of brain thrombosis. To our understanding, the mechanisms of large artery occlusion still remain uncertain.

Cardiovascular discovers began years before the cerebrovascular ones. Herrick ${ }^{9}$ was the first who described the clinical manifestations of coronary thrombosis in 1912, but not until the 1940s did cardiologist clarify the relationship between angina, coronary thrombosis, and MI. Later, postmortem studies showed a disrupted atheromatous plaque in $85 \%$ of coronary thrombi, suggesting that this is the most common mechanism implicated in acute coronary syndromes ${ }^{10,11}$. Furthermore, there is evidence that asymptomatic individuals could have silent plaque disruption in their coronary arteries $(9-22 \%)^{12}$. Mizuno et al. ${ }^{13}$ studied coronary artery lesions with angioscopy showing important differences in the type of thrombi depending on the classical syndrome. He found that patients with MI had predominantly red thrombi, and those patients with unstable angina had white thrombi, suggesting that arteries were still open. Now, it is clear that unstable plaques occur secondary to endothelial injury and exposure of the subendothelial matrix to the luminal contents explains the majority of coronary thrombosis. 
The concept of the unstable plaque has not been shown to be one of the main mechanisms involved in stroke. Media layer of the vessels is different between coronary and brain arteries. Cerebral arteries does not have external elastic laminae, implicating less flexibility properties. To our knowledge, there are no human angioscopic studies in intracraneal vessel published in the literature to characterize plaques.

When compared with MI, stroke is a more heterogeneous process with different mechanisms, including: embolic (cardiac or large artery source), hemodynamic, thrombotic, penetrating artery occlusion due to lipohyalinosis, and prothrombotic factors (deficit of protein S, C, etc).

As noted, data from cerebrovascular ischemia appeared almost one decade later than cardiovascular studies. This delayed and incomplete evidence of cerebrovascular mechanisms could be explained by 4 different causes ${ }^{14}:$ a) autopsy studies were performed in the 1960 s before knowledge of the morphology of atherosclerotic lesions; b) most of these studies analyzed the extent of the lesions, but did not study the severity of them; c) authors focused on the intimal lesions and not on the media layer; and d) the tendency to homologue the pathophysiological mechanisms between different organs.

\section{Biological markers}

Troponin I and T, CK-MB and others are biological and diagnostic markers in MI. They also are considered as well as prognostic factors.

Fibrinopeptide $\mathrm{A}(\mathrm{FpA})$ is a sensitive indicator of thrombin activity. FpA is elevated following stroke with $400 \%$ higher levels than controls ${ }^{15-17}$. Nevertheless, it is susceptible to other clinical conditions (e.g.: venipuncture, sample processing). D-dimer and fibrinogen are also elevated in the first weeks after cerebrovascular ischemia, suggesting that the acute phase following stroke is characterized by marked fibrin generation with relatively less fibrinolytic activity. FpA, d-Dimer and fibrinogen levels vary according to the stroke subtype, with mean normal values in small artery disease ${ }^{17,18}$ Elevated values of fibrin markers have been found in other clinical conditions. Thus, there are no specific and sensitive biological marker demonstrated in patients with stroke.

In summary, histological changes and ischemic mechanisms are the major differences between heart and brain vessels. Thus, these findings could reflect the controversial results in clinical trials.

\section{Antiaggregants in stroke}

Aspirin is the most common antiplatelet agent in clinical use today. Evidence supporting a role for aspirin in the prevention and treatment of ischemic cerebrovascular disease exists for less than 10 years. The safety and efficacy of ASA use in acute stroke was recently tested in two large trials (IST and CAST).

Although ASA is a relatively weak platelet antagonist, an approximately $23 \%$ risk reduction for ischemic stroke was shown in the Antiplatelets Trialists' Collaboration (ATC) metanalysis ${ }^{2}$. Other antiplatelet agents can also be useful. Ticlopidine can add almost $10 \%$ additional benefit over ASA (33\% risk reduction for MI, stroke or vascular death). Two major trials in patients with (transitory ischemic attack (TIA) and minor strokes have shown benefit of ticlopidine over placebo or ASA ${ }^{19,20}$ in secondary prevention of ischemic events. However, side effects as hematological complications limit the use of ticlopidine in clinical practice. Later, clopidrogrel, a thienopyridine analogous to ticlopidine, with less side effects, was synthesized. Both agents inhibit ADP-induced platelet aggregation by blocking ADP receptor on the platelets. CAPRIE (clopidogrel vs ASA in patients at risk of ischemic events) ${ }^{21}$ was a randomized, double-blinded study considering clopidogrel $75 \mathrm{mg}$ vs ASA $325 \mathrm{mg}$. 19185 patients with previous MI, stroke or peripheral vascular disease were included. The RRR for all ischemic events was $8.7 \%(\mathrm{p}=0.043)$ and for fatal or non fatal stroke it was 5.2\% ( $\mathrm{p}=.26)$. Clopidrogrel, can contribute with a $5.2 \%$ benefit over the ASA based on the CAPRIE study. 
The combination of ASA and dipyridamole versus placebo showed a $30 \%^{2}$ to $37 \%^{22}$ benefit in relative risk reduction (RRR), but only add an approximately $19 \%$ RRR when comparing to ASA alone. The ESPS 2 study $^{22}$ showed the most recent evidence in favor of combined therapy. In summary, the benefit (RRR) produced by the "best" antiplatelet regimen is lower than $40 \%$.

The absolute reduction varies considerably depending on the particular patient's risk, the stroke subtype and the nature and severity of occlusive cerebrovascular lesions. Excluding the patients with cardioembolic stroke who benefit with anticoagulants, and those with carotid artery stenosis, who potentially can benefit with endarterectomy, a large number of patients are treated with platelet antiaggregants. Of these, even considering the best antiagregant treatment, in approximately 65$70 \%$ this strategy will not be successful. Furthermore, individuals at very low risk for stroke seem to have the same relative reduction, but their risk may be so low that the "benefit" may be meaningless. Thus, we are still waiting for a more efficacious antiplatelet agent.

\section{THROMBOGENESIS AND THE ROLE OF GPIIB/IIIA RECEPTOR}

During the last decade a steadily increasing number of studies about the molecular and pathophysiological mechanisms implicated in atherogenesis and thrombosis have been published. Arterial occlusions are the result of a complex interaction between blood elements, disturbed flow, and vessel wall abnormalities ${ }^{23}$. Atheromatous plaques consist of two major components: a) the soft-lipid rich known as the "atheromatous" component, and b) the fibrous tissue called "sclerotic" 24 . When plaques fissure or ulcerate, the subendothelial matrix is exposed to the circulating blood. The dysfunctional endothelial layer and the exposure of the subendothelia matrix predispose to the adherence of circulating platelets. The first layer of platelets is the substratum for the assembly of coagulation proteins. This step constitutes the spreading of the atherogenic cascade. This process is mainly governed by several glycoprotein receptors residing on the cell's surface ${ }^{25,26}$. The process of platelet adherence is GPIb/IX complex mediated. GPIIb/IIIa is a platelet membrane receptor for fibrinogen and von Willebrand factor. GPIIb/IIIa receptors are found only on platelets and megakaryocytes, and their blockade therefore will not affect other cell types. GPIIb/IIIa is the only one that mediates the aggregation of adjacent platelets, being the central mechanism in the thrombus formation. This process is followed by a conformational change in the structure of the platelet GPIIb/IIIa receptor, platelet activation, turning platelets to bind adhesive glycoproteins with high affinity. Additional platelets are then recruited. This is where the up-regulated thrombotic mechanism has its greatest overall impact. Thus, the role of GPIIb/IIIa receptor is the limiting factor in the spreading of endothelial injury, and thrombosis can be prevented by their blockade. In addition, GPIIb/IIIa inhibitors have emerged as potentially the most effective class of agents that modulate platelet functions ${ }^{25-27}$.

\section{Plaque disruption: triggers and contributing factors}

Plaque disruption depends on its intrinsic properties (vulnerability) and extrinsic forces acting on them (triggers). The risk of rupture depends on plaque size, collagen content and thickness of the fibrous cap. Rupture is more frequent in the region where the plaque is thinnest and infiltrated with foam cells (lipid-filled macrophages) ${ }^{25-26}$.

Mechanical and hemodynamic forces can precipitate (or trigger) the disruption of a plaque. The arterial flow in a non-atherogenic vessel is laminar, producing a normal mechanical strength on the wall ranging from 1000 to $4000 \mathrm{mmHg}$. The mechanical stress produced in atherogenic vessels by the turbulent rapid flow range between 4000 and $7000 \mathrm{mmHg}$. The vessel layers as well as the plaque follow "Laplace's law", which says that wall tension directly depends on the radius of the vessel and its pressure. The higher the blood pressure and the larger the lumen, the more tension and risk of rupture. Experimental evidence suggests that rupture occurs adjacent to the site where mechanical stress is highest ${ }^{28,29}$. Other factors have been implicated, such as plaque compression, the longitudinal flexion, and the circumferential bending. However, evidence in the brain vessels is lacking. 
Epidemiological studies have shown that MI's and strokes occur at increased frequency in the morning, on Mondays, during the winter months, on cooler days and during vigorous exercise. The pathophysiological mechanisms are not completely understood, but the sympathetic nervous system has been implicated. Higher levels of blood catecholamines were associated with arousal, exercise, emotional stress that could partially explain the particular time at which of these ischemic events occur. There is also a seasonal variation in fibrinogen levels, being higher during the colder months, when the incidence and mortality of stroke and coronary heart disease are also higher ${ }^{30}$.

In summary, there are mechanical, pathological, prothrombotic and autonomic mechanisms triggered by different factors that contribute with the plaque disruption.

\section{NEW GPIIB/IIIA AGENTS}

The bulk of information about the new GPIIb/IIIa agents is provided by clinical trials in ischemic heart disease. Two models can be considered such as: a) coronary ischemic events secondary to angioplasty, and b) spontaneous coronary ischemia.

With the development of new treatment options, more controversies emerged. When coronary stenting was developed, patients who received stents were treated with a combination of antiplatelet agents and anticoagulants. Combined antiplatelet therapy (ticlopidine $250 \mathrm{mg}$ bid for 4 weeks + ASA vs heparin/coumadin + ASA) was compared in patients with acute MI. Ticlopidine treated group led to lower rates of stent vessel occlusion and hemorrhagic events and, at 6 months, a higher rate of survival without recurrent myocardial infarction. It is now clear that when compared with anticoagulants, aspirin and ticlopidine reduce both cardiac events and hemorrhage ${ }^{31}$.

GPIIb/IIIa inhibitors have emerged recently, such as: abciximab ${ }^{32,34}$, $\operatorname{tirofiban}^{35,37}$, lamifiban $^{38}$ and eptifibatide ${ }^{39}$. They have pharmacokinetic differences and were synthesized for parenteral use. Abciximab, a monoclonal antibody against the GPIIb/IIIa receptor was the first agent approved by FDA in the summer of 1998. More recently, tirofiban and eptifibatide were also approved. Abciximab could be the most effective, but there are no comparative trials between these drugs. The new development of carotid angioplasty and stenting, mimics the coronary procedures. Considering all studies together, the new GPIIb/IIIa antagonists have shown a 35\% RRR in death, MI or revascularization. Table 1 shows the design, RRR and stroke frequency of the major trials using GPIIb/IIIa antagonist in percutaneous angioplasty. These results could promise a new perspective, specially as adjuvant treatment for patients who have carotid stenosis procedures (endarterectomy, angioplasty or stent).

This evidence is the basis for the development of new oral agents such as: xemilofiban, orbofiban and sibrafiban. They were synthesized because of the need for continuing therapy after a thrombotic event may theoretically be necessary for thrombosis prevention.

\section{Controlled clinical trials in coronary syndromes}

The development of GPIIb/IIIa receptor antagonists represents an important advance in the medical management of ischemic heart disease. They are clearly effective and, when used properly, are relatively safe in patients undergoing percutaneous coronary intervention. Questions regarding the efficacy of GPIIb/IIIa inhibitors in various clinical settings (primary vs secondary prevention, acute vs chronic disease, coronary artery disease vs other thrombotic conditions); the optimal dose, and duration of treatment; the importance of concomitant aspirin and anticoagulants, the role of nonspecific antagonists which inhibit other integrin receptors; the long term risks and benefits of GPIIb/IIIa inhibition; and the cost-effectiveness of treatment with a GPIIb/IIIa represent a few of the outstanding issues still to be resolved. Table 2 summarizes the design, RRR and stroke frequency of the major trials using GPIIbIIIa in acute coronary syndromes (unstable angina and MI). The IMPACT-II study ${ }^{39}$ was the only one that reported the frequency of past medical history of stroke. There is an absence of published data considering cerebrovascular disease. 
Table 1. GPIIb/IIIa antagonist in percutaneous angioplasty

\begin{tabular}{|c|c|c|c|c|c|c|}
\hline Trial & $\mathrm{N}$ & Treatment groups & Design & $\begin{array}{l}\text { RRR } \\
\% *\end{array}$ & $\begin{array}{c}\text { Stroke } \\
\text { AD vs. P }\end{array}$ & End-Points \\
\hline & & Abciximab bolus & & & & \\
\hline EPIC $^{32}$ & 2,099 & $\begin{array}{c}\text { Abciximab bolus+ } \\
\text { infusion } \\
\text { Placebo } \\
\text { Abciximab + H(LD) }\end{array}$ & P-R-DB & 30 & NA & $\begin{array}{l}\text { D-NFMI-SR- } \\
\text { ICS-IBP }\end{array}$ \\
\hline EPILOG $^{33}$ & 2,792 & $\begin{array}{c}\text { Abciximab +H(SD) } \\
\text { Placebo + H }(\mathrm{SD}) \\
\text { Abciximab + H }\end{array}$ & P-R-DB & 58 & $\begin{array}{l}5 \text { vs. } 0 \\
\text { (NS) } \\
1 \text { vs. } 3\end{array}$ & D-NFMI-R \\
\hline CAPTURE $^{34}$ & 1,265 & $\begin{array}{c}\text { Placebo }+\mathrm{H} \\
\text { Placebo } \\
\text { Eptifibatide bolus + }\end{array}$ & P-R-DB & 47 & (NS) & D-NFMI-R \\
\hline IMPACT II $^{39}$ & 4,010 & $\begin{array}{l}\text { LD infusion } \\
\text { Eptifibatide bolus }+ \\
\text { HD infusion }\end{array}$ & P-R-DB & 18 & $\begin{array}{c}7 \text { vs. } 8 \\
\text { (NS) }\end{array}$ & $\begin{array}{c}\text { D-NFMI-SR- } \\
\text { R-ICS }\end{array}$ \\
\hline Overall & 12,485 & All drugs & P-R-DB & 35 & 13 vs. 11 & D-NF-MI-R \\
\hline \multicolumn{7}{|c|}{$\begin{array}{l}\text { RRR, relative risk reduction; AD, active drug; P, prospective; R, randomized; DB, } \\
\text { SD, standard-dose; D, death; NFMI, non-fatal myocardial infarction; SR, repeat pe } \\
\text { of coronary stent; IBP, intra-aorctic balloon pump; R, revascularization; NA, non a } \\
\text { *According to the rates of death or myocardial infarction at } 30 \text { days. } \\
\text { Table 2. GPIIb/IIIa antagonist in Unstable angina and Non-Q-Wave MI. }\end{array}$} \\
\hline Trial & $\mathrm{N}$ & Treatment groups & Stroke & & Design & $\operatorname{RRR} \%$ \\
\hline PRISM $^{36}$ & 3,232 & $\begin{array}{c}\text { Tirofiban } \\
\mathrm{H} \\
\text { Tirofiban+ H }\end{array}$ & NA & & R-DB & 18 \\
\hline PRISM-Plus $^{37}$ & 1,915 & $\begin{array}{l}\text { Tirofiban } \\
\text { H Lamifiban } \\
\text { (LD pr HD) }\end{array}$ & NA & & R-DB & 27 \\
\hline PARAGON $^{38}$ & 2,282 & $\begin{array}{l}\text { alone } \\
\text { Lamifiban } \\
(\mathrm{LD} \text { or HD) } \\
\quad+\mathrm{H} \\
\mathrm{H} \text { alone } \\
\text { Eptifibatide }\end{array}$ & NA & & R-DB & 12 \\
\hline PURSUIT $^{45}$ & 10,948 & $\begin{array}{c}+\mathrm{H} \\
\text { Placebo }+\mathrm{H}\end{array}$ & NA & & R-DB & 10 \\
\hline Overall & 18,032 & All drugs & NA & & R-DB & 17 \\
\hline
\end{tabular}

Abbreviations: same as Table 1, except for: LD, low-dose ( $1 \mu \mathrm{g} / \mathrm{min})$; and HD, high-dose $(5 \mu \mathrm{g} / \mathrm{min})$

There are few studies considering oral GPIIb/IIIa inhibitor agents. The ORBIT study ${ }^{40}$ included 549 patients undergoing PTC who were randomized to received oral xemilofiban or placebo. Patients in the placebo group also received ticlopidine. No stroke event was reported in the xemilofiban arm. The incidence of acute hemorrhagic events at 24 days was lower than $1 \%$. In the TIMI- 12 trial $^{41}$, sibrafiban a new oral GPIIb/IIIa inhibitor was studied in patients undergoing thrombolytic therapy for MI. $40 \%$ of the patients treated with $20 \mathrm{mg}$ of sifrafiban had a bleeding event, suggesting higher 
Table 3. Bleeding complications in GPIIb/IIIa trials.

\begin{tabular}{ccccc}
\hline & \multicolumn{2}{c}{ Major Bleeding (\%) } & \multicolumn{2}{c}{ Minor Bleeding (\%) } \\
TRIAL & Active drug & Placebo/C-Med & Active drug & Placebo/C-Med. \\
\hline EPIC $^{8}$ & 10.9 & 6.6 & NA & NA \\
EPILOG $^{9}$ & $3.5(\mathrm{HD})$ & 3.1 & $7.4(\mathrm{HD})$ & 3.7 \\
& $2.0(\mathrm{LD})$ & & $4.0(\mathrm{LD})$ & \\
CAPTURE $^{10}$ & 3.8 & 1.9 & 4.8 & 2 \\
IMPACT II $^{15}$ & $5.2(\mathrm{HD})$ & 4.8 & $\mathrm{NA}$ & NA \\
PARAGON $^{14}$ & $5.1(\mathrm{LD})$ & 0.8 & $\mathrm{NA}$ & NA \\
PRISM $^{12}$ & 1.5 & 0.4 & 2.0 & 1.9 \\
PRISM-PLUS $^{13}$ & 0.4 & 3.0 & NA & NA \\
\hline
\end{tabular}

C-Med, concomitant medication; HD, high-dose; LD, low-dose; NA, non-available

Table 4. Intracerebral hemorrhage with GPIIb/IIIa agents.

\begin{tabular}{lcc}
\hline & GPIIb/IIIa agent arm $(\%)$ & Placebo or C-med. arm (\%) \\
\hline EPIC $^{8}$ (abciximab) & $2 / 678(0.29)$ & $2 / 681(0.29)$ \\
EPILOG $^{9}$ (abciximab) & $4 / 1811(0.22)$ & $0 / 914(0)$ \\
CAPTURE $^{10}$ (abciximab) & $0 / 623(0)$ & $1 / 630(0.16)$ \\
PRISM $^{12}$ (tirofiban) & $1 / 992(0.1)$ & $1 / 1007(0.1)$ \\
PRISM-PLUS $^{13}$ (tirofiban) & $31 / 773(4.0)$ & $24 / 797(3.0)$ \\
IMPACT II $^{15}$ (Eptifibatide) & $3 / 2682(1.1)$ & $1 / 1328(0.7)$ \\
\hline
\end{tabular}

bleeding risk when GPIIb/IIIa agents followed the fibrinolytic therapy. However, more data in stratified subgroups is necessary to define their potential benefit.

\section{Related complications}

There are complications related to the new GPIIb/IIIa agents that can limit their wide use, such as: bleeding, thrombocytopenia, immune reactions and the potential risk of anaphylaxis.

\section{Major and minor bleeding}

The most feared side effect is major bleeding. Table 3 shows the incidence of major and minor bleeding in the main trials. In the EPIC trial $^{8}$ bleeding was two to three times more frequent in patients receiving abciximab than in those receiving placebo (EPIC). However, analysis of three major trials with abciximab has shown no increased risk of hemorrhagic stroke compared with placebo. Table 4 shows the incidence of hemorrhagic stroke.

\section{Thrombocytopenia}

Thrombocytopenia is most likely a class effect of the GPIIb/IIIa inhibitors and may occur either acutely within hours (mechanism unclear), or in a delayed fashion (5 to 10 days or later, a possible immunologic mechanism) following administration. The frequency of thrombocytopenia 
depends on the criteria and the classification. Slight thrombocytopenia (platelet count $<100,000 /$ $\mathrm{mm} 3$ ) was present in $5.2 \%, 5.6 \%$, and $2.5 \%$ in the abciximab group in the $\mathrm{EPIC}^{8}, \mathrm{CAPTURE}^{10}$, and EPILOG $^{9}$ trials respectively. In the placebo arm, the frequency of thrombocytopenia was $3.4 \%, 1.3$ and $1.4 \%$ respectively for the same trials.

In the IMPACT $\mathrm{II}^{15}$, the frequency of thrombocytopenia related to low-dose and high-dose eptifibatide was $3.2 \%$ and $2.8 \%$, respectively, compared to $2.7 \%$ in the placebo arm. In the RESTORE trial $^{11}$, the frequency of thrombocytopenia was $1.1 \%$ in the tirofiban group and $0.9 \%$ in the placebo arm. Despite the overall incidence of thrombocytopenia was lesser in the placebo arms, there was no statistically significant differences.

\section{GPIIB/IIIA INHIBITORS IN STROKE}

\section{Experimental evidence in stroke models}

Few studies have evaluated the new GPIIb/IIIa inhibitors in humans with stroke. Most of them are based on induced-carotid artery thrombosis. After recanalization following the use of thrombolytic agents, the residual thrombus and the release of mediators promotes platelet aggregation and vasoconstriction. This thrombogenic environment favors rethrombosis. Rebello et al. ${ }^{42}$ studied the ability of the new synthetic GPIIb/IIIa inhibitor (TP 9201) to prevent carotid artery rethrombosis in dogs. They induced carotid thrombosis by electrolytic injury. Once it was produced, they locally injected streptokinase to produce clot lysis. Carotid recanalization was followed by infusion of either placebo or active drug. They found a significant reduction in the thrombus mass in the highdose treated group, suggesting that new GPIIb/IIIa agents may play a therapeutic role in rethrombosis.

\section{Clinical evidence in stroke}

There are few anecdotal reports considering the new GPIIb/IIIa inhibitors in cerebrovascular disease. Wallace et $a .^{43}$ reported a 60 year-old patient with acute basilar artery occlusion who underwent revascularization with urokinase and angioplasty. Despite the repeated use of urokinase, angioplasty and the anticoagulation, the basilar re-thrombosed. Abciximab was administered before the final angioplasty, and the patient did well and the artery openned. Lempert et al. ${ }^{44}$ reported a 55 year-old women with intraventricular hemorrhage, whose angiogram revealed a bilobed top of the basilar aneurysm. She was treated with GDC, but serial angiography showed a marked thrombus enlargement arising from the coils and projecting to the left PCA. The patient received abciximab to prevent arterial occlusion. Angiography at day 2 and 6 month showed an occlusion of the aneurysm. Also, both PCAs were patent and there was no thrombus, suggesting the potential rescue treatment of abciximab in rethrombosis.

The PURSUIT investigators ${ }^{45}$ reported the frequency of stroke in patients with acute coronary syndromes. Among 10948 patients studied, they found $79(0.7 \%)$ with stroke. 66 had ischemic stroke, 6 had intracranial hemorrhages, 3 had hemorrhagic infarction and 4 had uncertain causes of stroke. No differences in the stroke rates between patients who received placebo and those assigned to eptifibatide were found. Seventeen (22\%) patients died within 30 days. Twenty-three (32\%) patients had moderate to severe deficits by hospital discharge or 30 days. The authors concluded that stroke was an uncommon event in patients with acute coronary syndromes in the PURSUIT trial, although associated with significant morbidity and mortality. There was neither more increased incidence of hemorrhagic stroke nor benefit in ischemic stroke rates among the eptifibatide treated group. This is also the first report considering stroke rates in a GPIIb/IIIa randomized trial.

This finding needs to be considered with caution because: a) the end-points of the study were death and non-fatal MI. Fatal or non fatal stroke were not considered, b) the population was at high risk for fatal events, and c) the low number of events (ischemic stroke) to reach statistical significance.

Although theoretically the GPIIb/IIIa inhibitors, as well as combined antiplatelet therapy are promising, more data are necessary in stroke populations since the current results are inconsistent. 


\section{Future perspectives}

There are two major ongoing trials involving GPIIb/IIIa inhibitors in stroke:

1-BRAVO (Blockade of the GPIIb/IIIa receptor to avoid vascular occlusion) study recently started in March 1999. Patients eligible to entry are those with TIA, stroke, MI, unstable angina, and PVD. Patients are randomized to lotrafiban or placebo PO. The primary end-points are MI, stroke or composite death.

2-The ReoPro study ${ }^{46}$ (abciximab in acute stroke) is being conducted in 25 centers in USA and 12 in Europe. Abciximab is a monoclonal antibody against platelet integrin GPIIb/IIIa. Patients presenting within $24 \mathrm{hs}$ of stroke onset are eligible for this study, stratified by time onset $(<12 \mathrm{hs}$ vs $>12 \mathrm{hs}$ ) and stroke severity (NIH scores 4-14 and >14) to receive four dose tiers of the study agent (abciximab or placebo). The primary end-point is day $5 \mathrm{ICH}$ frequency. Preliminary results showed that at 3 month of follow up, 35\% of the patients in the treated group vs. $20 \%$ in the placebo group had minimal or no residual deficit.

Therefore, the new GPIIb/IIIa inhibitors currently represent the most promising antiaggregant agents. The combination of antiplatelet drugs with different mechanisms of action could add more substantial benefit. Despite the rationale expectation of these agents, we await the results of the ongoing clinical trials.

\section{CONCLUSIONS}

1- Drug therapies that inhibit thrombus formation are important components of the management of the acute ischemic stroke.

2- The benefit in stroke prevention even using "best" antiaggregant regimen is lower than $40 \%$, supporting a role for the emerged new antiplatelet agents.

3- Several trials have demonstrated a relative risk reduction for different GPIIb/IIIa blockers in coronary syndromes, suggesting a potential role of these agents in the vascular ischemic syndromes.

4- We must make conclusions based on tested hypothesis. Now, further research is needed to confirm the potential benefit of the new GPIIb/IIIa inhibitors in cerebrovascular disease.

\section{REFERENCES}

1. Cairns JA, Gent M, Singer J, et al. Aspirin, sulfinpyrazone, or both in unstable angina: results of a Canadian multicenter trial. N Engl J Med 1985;313:1369-1375.

2. Antiplatelet Trialists' Collaboration. Collaborative overview of randomised trials of antiplatelet therapy-I: Prevention of death, myocardial infarction, and stroke by prolonged antiplatelet therapy in various categories of patients. BMJ 1994;308:81-106.

3. Virchow R. Ueber die akut Entzundung der Arterien. Virchows Arch Path Anat. 1847;1:272-378.

4. Foix $\mathrm{C}$, Hillemand $\mathrm{P}$, Ley $\mathrm{J}$. Relativement au ramollissement cerebral à sa frequence et à son siege, et a importance relative des obliterations arterielles completes ou incompletes dans sa pathologie. Rev Neurol 1927;43:217-218.

5. Fisher CM. Occlusion of the internal carotid artery. Arch Neurol 1951;65:346-377.

6. Fisher CM, Ojemann RG. A clinico-pathologic study of carotid endarterectomy plaques. Rev Neurol 1986;142:573-589.

7. Fisher M, Martin A, Cosgrove M, Norris JW. The NASCET-ACAS Plaque Project. Stroke 1993;24 (Suppl 1):24-25.

8. Ogata J, Masuda J, Yutani C, Yamaguchi T. Mechanisms of cerebral artery thrombosis: a histopathological analysis on eight necropsy cases. J Neurol Neurosurg Psychiatry 1994;57:17-21.

9. Herrick JB. Clinical features of sudden obstruction of the coronary arteries. JAMA 1912; 59:2015-2020.

10. Richardson PD, Davies MJ, Born GV. Influence of plaque configuration and stress distribution on fissuring of coronary atherosclerotic plaques. Lancet 1989;2:941-944.

11. Frink RJ. Chronic ulcerated plaques: new insights into the pathogenesis of acute coronary disease. J Invasive Cardiol 1994;6:173-185.

12. Davies MJ, Bland JM, Hangartner JR, Angelini A, Thomas AC. Factors influencing the presence or absence of acute coronary artery thrombi in sudden ischaemic death. Eur Heart J 1989;10:203-208.

13. Mizuno K, Satomura K, Miyamoto A, et al. Angioscopic evaluation of coronary-artery thrombi in acute coronary syndromes. N Engl J Med. 1992;326:287-291.

14. Caplan LR. Cerebral ischemia and infarction in blacks. In Gillium RF, Gorelick PB, Cooper ES. Stroke in blacks. Basel: Karger, 1999:7-18.

15. D'Angelo A, Landi G, D'Angelo VS, et al. Protein C in stroke. Stroke 1988,19:579-583.

16. Feinberg WM, Bruck DC, Ring ME, Corrigan JJ Jr. Hemostatic markers in acute stroke. Stroke 1989;20:592-597. 
17. Takano K, Yamaguchi T, Uchida K. Markers of a hypercoagulable state following acute ischemic stroke. Stroke 1992;23:194-198.

18. Fisher M, Francis R. Altered coagulation in cerebral ischemia: platelet, thrombin, and plasmin activity. Arch Neurol 1990;47:1075-1079.

19. Hass WK, Easton JD, Adams HP Jr, et al. A randomized trial comparing ticlopidine hydrochloride with aspirin for the prevention of stroke in high-risk patients. Ticlopidine Aspirin Stroke Study Group. N Engl J Med 1989;321:501-507.

20. Gent M, Blakely JA, Easton JD, et al. The Canadian American Ticlopidine Study (CATS) in thromboembolic stroke: design, organization, and baseline results. Stroke 1988;19:1203-1210.

21. CAPRIE Steering Committee. A randomised, blinded, trial of clopidogrel versus aspirin in patients at risk of ischemic events. Lancet 1996;348:1329-1333.

22. Vane JR, Meade TW. Second European Stroke Prevention Study (ESPS 2): clinical and pharmacological implications. J Neurol Sci 1997;145:123-125.

23. Falk E, Shah PK, Fuster V. Coronary plaque disruption. Circulation 1995;92:657-671.

24. Rosenschein U, Ellis SG, Yakubov SJ, Haudenschild CC, Dick RJ, Topol EJ. Histopathologic correlates of coronary lesion angiographic morphology: lessons from the directional atherectomy experience. Corn Artery Dis 1992;3:953-961.

25. Spencer F, Becker R. Platelets: structure, function, and their fundamental contribution to hemostasis and pathologic thrombosis. In Becker RC (ed). Textbook of coronary thrombosis and thrombolysis. Boston, MA: Kluwer Academic Publ, 1997:24-37.

26. Becker R. Thrombosis and the role of the platelet. Am J Cardiol 1999;83(9A):3E-6E.

27. Weisel J, Nagaswami C, Vilaire G, Bennett J. Examination of the platelet membrane glycoprotein IIb/IIIa complex and its interaction with fibrinogen and other ligands by electronic microscopy. J Biol Chem 1997;267:1663-1667.

28. Cheng GC, Loree HM, Kamm RD, Fishbein MC, Lee RT. Distribution of circumferential stress in ruptured and stable atherosclerotic lesions: a structural analysis with histopathological correlation. Circulation 1993;87:1179-1187.

29. Chen PS, Feld GK, Kriett JM, et al. Relation between upper limit of vulnerability and defibrillation threshold in humans. Circulation 1993;88:186-192.

30. Muller JE, Abela GS, Nesto RW, Tofler GH. Triggers, acute risk factors and vulnerable plaques: the lexicon of a new frontier. Am Coll Cardiol 1994;23:809-813.

31. Schomig A, Neumann FJ, Walter H, et al. Coronary stent placement in patients with acute myocardial infarction: comparison of clinical and angiographic outcome after randomization to antiplatelet or anticoagulant therapy. J Am Coll Cardiol 1997;29:28-34.

32. The EPIC Investigators. Use of a monoclonal antibody directed against the platelet glycoprotein IIb/IIIa receptor in highrisk coronary angioplasty. N Engl J Med 1994;330:956-960.

33. The EPILOG Investigators: Platelet glycoprotein IIb/IIIa receptor blockade and low-dose heparin during percutaneous coronary revascularization. N Engl J Med 1997;336:1689-1696.

34. The CAPTURE Investigators. Randomised placebo-controlled trial of abciximab before and during coronary intervention in refractory unstable angina. Lancet 1997; 349:1429-1435.

35. The RESTORE Investigators. Effects of platelet glycoprotein IIb/IIla blockade with tirofiban on adverse cardiac events in patients with unstable angina or acute myocardial infarction undergoing coronary angioplasty. Circulation 1997;96:1445-1453.

36. The PRISM Investigators. A comparison of aspirin plus tirofiban with aspirin plus heparin for unstable angina. $\mathrm{N}$ Engl $\mathrm{J}$ Med 1998;338:1498-1505.

37. The PRISM-PLUS Investigators. Inhibition of the platelet glycoprotein IIb/IIIa receptor tirofiban in unstable angina and non-Q-wave myocardial infarction. N Engl J Med 1998;338:1488-1497.

38. The PARAGON Investigators. International, randomized, controlled trial of lamifiban, heparin or both in unstable angina. Circulation 1998;97:2386-2395.

39. The IMPACT-II Investigators. Randomized placebo-controlled trial of effect of eptifibatide on complications of percutaneous coronary intervention. Lancet 1997;349:1422-1428.

40. The ORBIT Investigators. Pharmacodynamic efficacy, clinical safety, and outcomes after prolonged platelet glycoprotein IIb/IIIa receptor blockade with oral xemilofiban: results of a multicenter, placebo-controlled, randomized trial. Circulation 1998;98:1268-1278.

41. The TIMI-12 Investigators. A randomised trial of an oral glycoprotein IIb/IIIa antagonist, sibrafiban, in patients post and acute coronary syndrome: results from the TIMI-12 trial. Circulation 1998;97:340-349.

42. Rebello SS, Driscoll EM, Lucchesi BR. TP-9201, a glycoprotein IIb/IIIa platelet receptor antagonist, prevents rethrombosis after successful arterial thrombolysis in the dog. Stroke 1997;28:1789-1796.

43. Wallace RC, Furlan AJ, Moliterno DJ, Stevens GH, Masaryk TJ, Perl J $2^{\text {nd }}$. Basilar artery rethrombosis: successful treatment with platelet glycoprotein IIa/IIIa receptor inhibitor. AJNR 1997;18:1257-1260.

44. Lempert TE, Malek AM, Halbach VV, Phatouros CC, Dowd CF, Higashida RT. Rescue treatment of acute parent vessel thrombosis with glycoprotein IIb/IIIa inhibitor during GDC coil embolization. Stroke 1999;30:693-695.

45. Mahaffey KW, Harrington RA, Simoons ML, et al. Stroke in patients with acute coronary syndromes: incidence and outcome in the platelet glycoprotein IIb/IIIa in unstable angina. Receptor suppression using integrilin therapy (PURSUIT) trial. The PURSUIT Investigators. Circulation 199911;99:2371-2377.

46. Adams HP, Bogousslavsky J, Barnathan E, Polzer J, Leclerc JR. Preliminary safety report of a randomised, double-blinded, dose escalation trial of abciximab (ReoPro) in acute ischemic stroke. Cerebrovasc Dis 1999;9(Suppl 1):127. 